\title{
Joint Discussion 10 Progress in planetary exploration missions
}

\author{
Guy Consolmagno (ed.) \\ Specola Vaticana, VA-00120 Citta del Vaticano, Vatican City State \\ email: gjc@as.arizona.edu,gjc@specola.va
}

\section{Preface}

The astronomical study of planets is as old as Galileo's telescope, but in a profound way it was reborn with the advent of the Space Age. By constructing probes capable of leaving the surface of the Earth and traveling to other places in our solar system, sending back data collected from the very places that the astronomers wished to study, for the first time we were freed from the restrictions of observing astronomical objects from afar. These in-situ measurements, in their turn, have inspired countless new research projects back on Earth, from laboratory studies of materials to telescopic observations, of objects and in wavelengths now known to be of astronomical interest, thanks to those probes.

The year 2006 marked the end of the first fifty years of the Space Age, begun with the launch of Sputnik in October, 1957. It also concluded a remarkable triennium which saw the first sample returns of materials from space since the end of the Soviet and American lunar programs more than thirty years ago; the first major planetary missions from Western Europe; and the first successful interplanetary space mission from Japan.

At the Joint Discussion 10 of the triennial General Assembly of the IAU in Prague, August 2006, the results of planetary spacecraft missions that returned their first results since 2003 were summarized by the project scientists and other principal investigators of the missions. In organizing this Joint Discussion, we recognized that planetary astronomy extends far beyond the results of spacecraft missions alone. Thus, we encouraged the speakers to relate their new results to highlight the body of work in Planetary Sciences that has proceeded in parallel with the spacecraft missions.

By concentrating on the results from recent spacecraft missions in these proceedings, we hope we have accomplished three goals of interest to the larger IAU community:

(i) First and foremost, we present results that are intrinsically interesting, even for those of us not directly involved in planetary sciences.

(ii) In addition, these papers provide a context in which the wider accomplishments of the planetary astronomy community can be described, and results that can have an impact on other fields of astronomy ranging from nucleosynthesis, to star-formation, to the evolution of solar-type stars.

(iii) And finally, by concentrating specifically on the high-profile space missions which have already been widely publicized in the general media, the proceedings of this Joint Discussion provide in-depth information which our fellow astronomers can take back to their home institutions and help them answer the kinds of questions that the general public might ask about these missions.

The brief papers presented here could not possibly summarize all of the interesting results of those missions. Instead, it has been our intent to provide, in one place, an overview of the outlines of each mission; and a guide to the literature that can serve as a starting point for anyone wishing to look more deeply into the results of these programs. 
In the Joint Discussion itself, results from the Cassini-Huygens mission to Saturn and Titan were also presented. Unfortunately, the principle investigators of that mission were not able to provide a written summary of their mission in time to be published here.

\section{Missions reviewed}

\begin{tabular}{|c|c|c|c|c|c|c|}
\hline Mission & Target & Principal Scientist & Agency & $\underline{\text { Launch }}$ & $\underline{\text { Arrival }}$ & $\underline{\text { Return }}$ \\
\hline Spirit/Opportunity & Mars & W. Bruce Banerdt & NASA & 2003 & 2004 & \\
\hline Mars Express & Mars & in F. Chicarro & $\mathrm{ESA}$ & & 2004 & \\
\hline Cassini & Saturn & s L. Matson & $\mathrm{SA}$ & & 2004 & \\
\hline Sta & Comet & nlee & & 999 & 2004 & 2006 \\
\hline & Solar Wind & Dol & & & 2004 & 2004 \\
\hline Hu? & Titan & reton & ESA & 2004 & 2004 & \\
\hline SMAI & Mo & Foing & ES & 2003 & 2005 & \\
\hline Hayabusa & Asteroid & Akira Fujiwara & JAXA & 2003 & 2005 & $2010 ?$ \\
\hline Deep Impact & Comet & Michael F. A'Hearn & NASA & 2005 & 2005 & \\
\hline Venus Express & Venus & L. Hakan Svedhem & ESA & 2005 & 2006 & \\
\hline
\end{tabular}

\section{Scientific Organizing Committee}

Guy J. Consolmagno (Vatican City State, chair), Michael F. A'Hearn (USA), Carlo Blanco (Italy), Regis Courtin (France), Dale P. Cruikshank (USA), Walter F. Huebner (USA), Peter M.M. Jenniskens (the Netherlands), H. Uwe Keller (Germany), Leonid V. Ksanfomality (Russia), Mikhail Ya. Marov (Russia), Melissa A. McGrath (USA), Keith S. Noll (USA), Maarten C. Roos-Serote (Portugal), Edward F. Tedesco (USA), and Iwan P. Williams (UK).

Guy J. Consolmagno, chair SOC

Vatican City State, November 30, 2006 